The total value of all the minerals worked in the kingdom was $69,088,366 l$., from which it will be seen that the value of the coal alone was practically five-sixths of the whole amount.

The number of separate accidents in mines was 886 , involving the loss of 1065 lives, of which 147 were the victims of four explosions of fire-damp or coal-dust. The number of separate accidents in quarries was II 7 , in which 124 lives were lost.

A comparative table showing the death-rates from mining and quarrying accidents in different countries per I000 persons employed, brings out some remarkable facts. Taking the column which represents the total for underground and surface for the year 1896 , or in the absence of the figures for 1896 those of 1895 , we find the following rates for the coal mines in some of the principal coal-producing countries of the world:-

\begin{tabular}{|c|c|c|c|c|c|}
\hline Belgium ... & $\ldots$ & $\ldots$ & $\cdots$ & $\cdots$ & $1 \cdot 14$ \\
\hline France (1895) & $\ldots$ & $\ldots$ & $\ldots$ & $\ldots$ & $\mathrm{I} \cdot 19$ \\
\hline German Empire & $\ldots$ & $\ldots$ & $\ldots$ & $\ldots$ & 2.57 \\
\hline Russia (1894) & $\ldots$ & $\ldots$ & $\ldots$ & $\ldots$ & $1 \cdot 29$ \\
\hline United Kingdom & $\ldots$ & $\ldots$ & $\ldots$ & $\ldots$ & I 48 \\
\hline \multicolumn{6}{|c|}{ United States (1895):- } \\
\hline Colorado & $\ldots$ & $\ldots$ & $\ldots$ & $\ldots$ & \\
\hline Illinois & $\ldots$ & $\ldots$ & $\ldots$ & $\ldots$ & I.94 \\
\hline Indiana & $\ldots$ & $\ldots$ & $\ldots$ & $\ldots$ & $2 \cdot 70$ \\
\hline Indian Territ & ory & $\ldots$ & $\ldots$ & $\ldots$ & I.64 \\
\hline Kentucky & $\ldots$ & $\ldots$ & $\ldots$ & $\ldots$ & $\mathrm{I} 02$ \\
\hline Missouri & $\ldots$ & $\ldots$ & $\ldots$ & $\ldots$ & $2 \cdot 07$ \\
\hline New Mexico & $\ldots$ & $\cdots$ & $\ldots$ & $\ldots$ & $16 \cdot 88$ \\
\hline Ohio .. & $\ldots$ & $\ldots$ & $\ldots$ & $\cdots$ & $2 \cdot I J$ \\
\hline \multicolumn{6}{|c|}{ Pennsylvania :- } \\
\hline Anthre & & $\ldots$ & $\cdots$ & $\cdots$ & 2.924 \\
\hline Bitun & & & $\ldots$ & $\ldots$ & 1.825 \\
\hline Utah $\ldots$ & $\ldots$ & $\ldots$ & $\ldots$ & $\ldots$ & $1 \cdot 50$ \\
\hline
\end{tabular}

According to M. Louis Lacombe, who compared the deathrates from accidents in mines in quinquennial periods, the last of which was 1890 to 1895 , the ratios are as follows :-

Russia $2 \cdot 90$, Belgium 2*38, England 2.18, France $1 \cdot 37$.

The death-rate from accidents to railway servants in the United Kingdom for the year 1896 is given as $1{ }^{\circ} \mathrm{O} I$ per 1000 . The category includes such classes as carmen $0^{\circ} 47$, clerks $0^{\circ} \mathrm{I} 7$, mechanics $0^{\prime} 33$, and signalmen $0^{\circ} 55$, whose occupations are not by any means dangerous. On the other hand, the death-rate amongst those who have to do with coupling and uncoupling and making up the trains is infinitely more serious, such as shunters $4^{\circ} 94$, yardsmen, $3^{\circ} 27$, guards and brakesmen of goods trains $3^{\circ} \mathrm{o3}$. The highest of these figures pales before those applicable to sailing ships, amongst which we find :-

$$
\begin{array}{lllll}
\text { British sailing ships (1896) } & \ldots & \ldots & \ldots & \text { I2:9 } \\
\text { German },, ~(1893) & \ldots & \ldots & \ldots & \text { 15 } 5
\end{array}
$$

These figures prove conclusively that the miner's calling, when brought into comparison with some other kinds of employment, is not of such a dangerous nature as is generally supposed. As having a bearing upon this question, however, it may be stated that one of the most gratifying features of the report is the curve given on Plate 4, which shows the death-rate per Iooo persons employed underground in coal-mines to have been reduced from the appalling figure of $5^{\circ} 5$ in $185^{1}$ to $1^{\circ} 62$ in 1896 . This result-upon the attainment of which the Home Office, the Inspectors of Mines, and the mining community generally may well be congratulated-is undoubtedly due to the efforts that have been made by means of legislation and inspection to remove the causes which formerly led to such a lamentable loss of life. The loss of 147 lives in four great explosions in the year 1896 is a black spot in the record which ought never to have been there. I am glad to observe that the year 1897 has been entirely free from anything of the same kind, and $I$ feel confident that if the new regulations regarding the watering of dusty places, and the use of explosives are attended to, or enforced with unflinching severity, we shall have seen the very last of such affronts to humanity and common sense.

The fines imposed upon owners and managers of mines for contraventions of the Mines Acts amounted to the insignificant sum of $258 l$. I $3 s$. 9d., while the workmen for similar offences paid $459 l .6 s$. $8 d$.

The outputs of coal from a few of the principal coal-producing countries were as follows :-

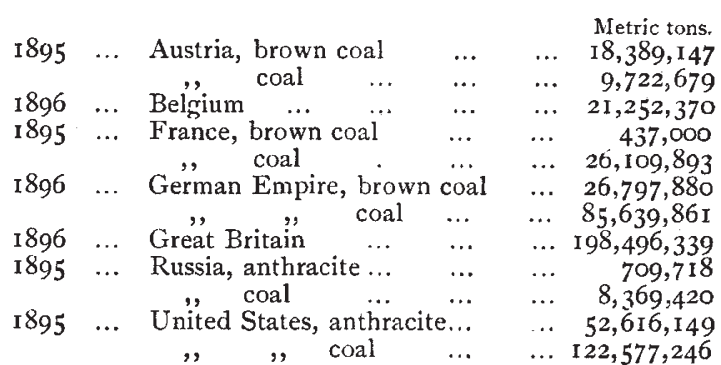

From these figures, with which I propose to bring this short and necessarily fragmentary notice to a close, it will be seen that this country still heads the list; but the United States are quickly overtaking us, and will, no doubt, come into the first position in the course of the next few years.

W. Galloway.

\section{CALCIUM CARBIDE AND ACETYLENE.}

$A \Gamma$ the meeting of Institution of Civil Engineers on March

I5, a paper on "Calcium Carbide and Acetylene" was .ead by Mr. Henry Fowler, and is here abstracted.

Acetylene was first isolated by E. Davy in 1837 from potassium carbide, a by-product of Sir H. Davy's method of manufacturing potassium. In the middle of the century Berthelot investigated its properties, and Wöhler produced it from calcium carbide. During the past few years it has assumed commercial importance owing to the development of the electric furnace, in which calcium carbide can be readily produced from lime and carbon. The furnaces used consist essentially of crucibles with carbon rods forming the positive electrode and a bottom plate lined with carbon for the negative. In the more recent furnaces these crucibles are mounted on small trollies so that they may be run out of the furnace when ready and a fresh one inserted without loss of time. The carbide formed is' a hard; dense substance of reddish colour, unacted upon by most of the ordinary reagents. It is, however, rapidly decomposed by water into acetylene and lime, giving $5^{\circ} 9$ cubic feet of acetylene, at a temperature of $60^{\circ}$ $\mathrm{F}$, and a pressure of 30 inches of mercury, per $1 \mathrm{lb}$. of carbide. As the power required theoretically to produce I $\mathrm{lb}$. of calcium carbide in an electric furnace is more than 2 H.P. hours, its manufacture is at present restricted to localities where power is cheap, as for instance where water-power is available.

Acetylene is a colourless gas with an intensely penetrating odour, and is slightly soluble in water, and extremely so in some other fluids. It is endothermic, giving 407 calories per cubic foot, whereas theoretically its value is 336.5 calories. As an illuminant it gives the most brilliant light of all gases, 5 cubic feet per hour under suitable conditions giving 240 candle-power. For small consumptions, however, this value is not obtained, and ordinary burners after a short time became clogged with soot. The latter defect can be overcome by the use of an injector burner, which, however, requires a higher pressure. Various diluents have been suggested, but have not been tried on a practical scale. The flame has a high actinic value, and causes light colours to appear lighter, and dark colours darker than when exposed to sunlight. The gas, when inhaled, combines with the hremoglobin and renders the blood incapable of taking up oxygen, and thus causing suffocation. It has, however, been shown tha' it is no more dangerous in this respect than coal gas.

Acetylene unites with copper, in the presence of moisture and ammonia, forming copper acetylide, and this when in a dry state is violently explosive. Silver is similarly acted upon.

Owing to the difficulty of obtaining the materials used in producing calcium carbide in a pure state, phosphoretted and sulphuretted hydrogen and ammonia are often found in the gas, and these should be removed by passing the gas through water and an acidified solution of a metallic salt. Nearly all proportions of air and acetylene are explosive, the gas itself being decomposed at $780^{\circ} \mathrm{C}$. At higher pressures than 2 atmospheres, if this temperature is attained by a part of the gas, it is communicated throughout the whole mass and a violent explosion occurs, which causes the pressure to rise to eleven times the initial pressure ; but owing to cooling by radiation, \&c., this is not reached in practice. Acetylene can be readily liquefied, having a critical temperature of $37^{\circ} \mathrm{C}$. and pressure of 68

No. 483 , voL. 57$]$ 
atmospheres. The resulting liquid is very light and has a high coefficient of expansion. Although this is a convenient method of storing a large quantity of gas in small bulk, it is unsafe, because of the ease and violence with which it explodes. The gas is extremely soluble in acetone; it has been suggested that this property might be used for its storage, but it has been shown that acetylene does not, even when thus dissolved, lose all its explosive properties.

Numberless derices for generating acetylene have been in. vented; its application, however, is more dependent upon the cost than upon the apparatus used in the manufacture. With calcium carbide at $16 \%$. per ton, it can compete with coal gas at 2s. $6 d$. per thousand cubic feet, when flat flanes are used for the latter, and a light of not less than 30 candles is required. This renders the gas peculiarly suited for buildings in which coal gas is not obtainable. It has been used for lighting a station on the Great Southern and Western Railway of Ireland, and at the Salford Docks of the Manchester Ship Canal. In the latter case, special portable generators are used which can be carried to any part of the docks, and which may be placed on the quay side and the gas led away to lamps placed in the holds of vessels. Amongst many other uses suggested are the lighting of lighthouses, lightships, buoys, military signals, \&c., as a standard of light, \&c. The price prevents its use for gas-engine driving. This reason also prohibits its use as an enricher of coal gas, as with low percentages the increase is not above I candle-power for I per cent. of acetylene. With "blue" watergas it is even less applicable, as more than ro per cent is required before any illumination is obtained. Methane and nitrogen are claimed to carry the gas without affecting its illuminating power.

\section{UNIVERSITY AND EDUCATIONAL INTELLIGENCE.}

Mr. R. T. GLAZEBrook, F.R.S., has accepted the post of Principal of University College, Liverpool.

DR. H. W. M. TIMS has been appointed professor of zoology in Bedford College, in succession to Dr. Benham.

Mr. Amos R. Eno, the New York multi-nillionaire, who died a few weeks ago, left 50,000 dollars to Amherst College.

Miss Catherine W. Bruce, of New York, will give to the Yerkes Observatory, Chicago University, a photographic telescope of to inches aperture and 60 inches focal length.

The bequest by Catherine M. Garcelon, of California, to Bowdoin College, Maine, amounting to several hundred thousand dollars, has been confirmed by the Supreme Court of the United States.

THE proposal to establish a chair of Anthropology and Anatomy, and also a chair of Physiology, in the University of St. Andrews, has been sanctioned by the University Court, and a scheme will be prepared.

THE proposal to create a special degree of Doctor of the University of Paris (as distinct from doctor of a particular faculty) has been approved by the Superior Council of Public Instruction, and will shortly be carried into effect.

Amovis the degrees conferred at the annual graduation ceremony of the University of St. Andrews on March 25, was the honorary degree of L.L.D., upon Prof. G. B. Howes, F.R.S., and the degree of D.Sc. upon Mr. A. T. Masterman.

THE recent decision of the Government, abolishing building grants from Imperial funds to schools and institutions under the Department of Science and Art, has created dissatisfaction. A joint deputation of the County Councils Association, the Association of Municipal Corporations, and the Association of Technical Institutions waited upon Sir John Gorst at the Privy Council last week to point out the inconvenierice caused by the withdrawal of the grants without previous notice; ard Sir John Gorst promised to bring the views of the deputation before the President of the Council.

\section{SCIENTIFIC SERIALS}

THE Toumal of Electricity, published in San Francisco, contains accounts of several large schemes for the electrical transmission of power in California. In one of these the water furnishing the power required for lighting Blue Lakes City, and several neighbouring townships, is conducted from the Blue Lakes, situated near the summit of the Sierra Nevada Mountains; while another installation at Bakersfield derives its power from the Kern River canyon. The "Wild West" is certainly making great strides in the practical applications of electricity.

In the current number of the Physical Review, Miss Isabelle Stone writes on the electric resistance of thin films ; Mr. Ed. ward B. Rosa describes a new form of electric curve-tracer; and Mr. C. H. Wind propounds a new theory of magneto-optic phenomena, the paper being a translation of one published by the Amsterdam Academy of Science.-Prof. C. Barus describes a method of obtaining pores or capillary canals of specified diameter; and Mr. C. P. Matthews discusses the methods of measuring mean horizontal candle-power of glow lamps, considering more especially the plan of rapidly whirling the lamp.

The latest number of the Mathematical Gazette, published under the auspices of the Mathematical Association, contains papers by Mr. E. Budden, on the conic through any five points; by Prof. Lloyd Tanner, on a class of algebraic func. tions; and a notice, by Dr. F. S. Macaulay, of an article by Miss C. A. Scott on Cayley's theory of the absolute. The functions to which Prof. Tanner's paper refers are those which involve only the differences of their arguments, and to which the same diaphoric was given by Cayley; and the object of the note is to suggest that an elementary discussion of these functions would be a valuable addition to the usual school course in algebra.

Symons's Monthly Meteorological Magazine, March.-West of England snowstorm, February 2r. The fall commenced, roughly speaking, about 5 h. p.m., and lasted until noon on the 22 nd. The heaviest storms occurred in Hants, Dorset, Devon and Somerset. The fall reached, or exceeded, 12 inches over the area contained between two lines, the northern one running about E.S.E. from Watchet, through Yeovil to Lymington, and the southern one from Portlock, through Tiverton to Bridport; say about sixty by twenty miles. The greatest depth, about 24 inches, occurred nearly centrally in this belt, between Milverton and Crewkerne.--Results of meteorological observations at Camden Square for forty years (for February). It is interesting to note the exceptional temperature and rainfall of last February in connection with the mean of $185^{8-97}$, at Camden Square (N.W. London): maximum temperature in $1898,56^{\circ} \cdot 2 ;$ minimum, $24^{\circ} 3$. Mean of all highest maxima of previous forty years, $55^{\circ} \cdot 2$; mean of all lowest minima, $24^{\circ} \cdot 1$. Rainfall in 1898, I.08 inches; mean of forty years, 161 inches.

THE Fournal de Physique for March contains papers on the following subjects :-On the magnetic torsion of iron and steel, by M. G. Moreau, in which the following laws are established: (I) at a point of a twisted wire outside the magnetic field the mag. netic torsion is proportional to the torsion of the wire, to the square of the intensity of the field if the latter is weak, and independent of the diameter of the wire; $(2)$ for points situated on different sides of the field the magnetic torsion has equal and opposite values if the ends of the wire are symmetrically placed with regard to the field; (3) along the length of the wire the torsion increases in proportion to the distance from the nearest end; it attains a maximum at the edge of the field, and vanishes at points inside the latter. The field in question is supposed to be a uniform field bounded by two parallel planes, beyond which the magnetic force vanishes.-M. Marage contributes a paper on ear-trumpets studied by the use of Koenig's flames. - M. G. Weiss describes an ingenious method, due to Hermann, of expanding any periodic curve in Fourier's series up to the first forty terms. The curve being drawn, forty equidistant ordinates are taken and measured, and correspond ing to each ordinate a series of products is obtained from a table prepared by Hermann; and these are entered in columns on quadrille paper. Finally a series of perforated cards are placed on the table thus formed; and to read off any coefficient in the expansion it is only necessary to algebraically sum the numbers seen through the openings in the corresponding card.-M. G. Charpy discusses entectic alloys, his paper being illustrated by figures showing their microscopic structure. - M. Gerrit Bakker, writing on perfect gases, gives a simple mathematical proof of the theorem that of the three characteristic laws of such gases, Boyle's, Charles's, and Joule's ; any one is deducible from the other two.

$$
\text { No. I } 483 \text {, VOL. } 57]
$$

